The Astrophysical Journal, 502:652-660, 1998 August 1

(C) 1998. The American Astronomical Society. All rights reserved. Printed in U.S.A.

\title{
GRAIN SURFACE CHEMISTRY: MODIFIED MODELS
}

\author{
Osama M. SHalabieA ${ }^{1}$ \\ Department of Physics, Ohio State University, Columbus, OH 43210 \\ PaOla CASElli \\ Osservatorio Astrofisico di Arcetri, Largo Enrico Fermi 5, I-50125 Firenze, Italy \\ AND \\ ERIC HERBST \\ Departments of Physics and Astronomy, Ohio State University, Columbus, OH 43210; herbst@mps.ohio-state.edu \\ Received 1997 November 19; accepted 1998 March 6
}

\begin{abstract}
The rate equation approach to the chemistry occurring on grain surfaces in interstellar clouds has been criticized for not taking the discrete nature of grains into account. Indeed, investigations of simple models show that results obtained from rate equations can be significantly different from results obtained by a Monte Carlo procedure. Some modifications of the rate equations have been proposed that have the effect of eliminating most of the differences with the Monte Carlo procedure for simplified models of interstellar clouds at temperatures of $10 \mathrm{~K}$ and slightly above. In this study we investigate the use of the modified rate equations in more realistic chemical models of dark interstellar clouds with complex gasgrain interactions. Our results show some discrepancies between the results of models with unmodified and modified rate equations; these discrepancies are highly dependent, however, on the initial form of hydrogen chosen. If the initial form is mainly molecular, at early stages of cloud evolution there are some significant differences in calculated molecular abundances on grains, but at late times the two sets of results tend to converge for the main components of the grain mantles. If the initial form is atomic hydrogen, there are essentially no differences in results between models based on the unmodified rate equations and those based on the modified rate equations, except for the abundances on grains of some minor complex molecules. Thus, the major results of previous gas-grain models of cold, dark interstellar clouds remain at least partially intact.
\end{abstract}

Subject headings: dust, extinction - ISM: molecules - molecular processes

\section{INTRODUCTION}

Although the gas-phase chemistry of interstellar clouds has been modeled successfully by a variety of authors, combined models of the gas-phase and grain chemistry have been less successful and certainly less widespread. There are several principal difficulties which have afflicted attempts to model the chemistry occurring on interstellar grains: (1) a poor understanding of the exact nature of the grain surfaces, (2) limitations on our knowledge of surface chemistry at low temperatures, and (3) problems in the actual modeling of time-dependent grain chemistry. Although difficulties 1 and 2 are being remedied both by observations such as those conducted with Infrared Space Observatory (ISO) and by laboratory investigations, difficulty 3 has remained.

There are two main schools of grain chemistry. In one, which under most circumstances is theoretically the more precise, interstellar grain surface chemistry is normally limited by the rate at which reactive gases are transported to the surface (the "accretion" limit) and not by surface reaction rates (the "reaction" limit) once the species are adsorbed. In the accretion limit, successive reactive species sticking to a particular grain are likely to react with one another if at least one of them migrates on the grain rapidly enough to find its co-reactant before yet another reactive species is adsorbed. In this situation, rate coefficients describing the actual diffusive rate of adsorbed reactive species play a limited role, and the chemistry can be approximated by following the sticking of successive species to a

\footnotetext{
${ }^{1}$ Permanent address: Department of Astronomy, Faculty of Science, Cairo University, Egypt.
}

grain in a Monte Carlo manner. This approach has been established mainly for time-independent chemical models (Hollenbach \& Salpeter 1971; Allen \& Robinson 1977; Tielens \& Hagen 1982; Tielens \& Allamandola 1987; Charnley, Tielens, \& Rodgers 1997; Tielens \& Charnley 1997). Unfortunately, despite vast increases in computing power over the last decade, nobody has yet succeeded in coding the Monte Carlo formulation within a timedependent chemical model of interstellar clouds.

The second and more tractable approach to grain chemistry makes use of rate equations analogous to those used for gas-phase models. Started by Pickles \& Williams (1977), this approach has been used by a variety of investigators in the last decade or so (d'Hendecourt, Allamandola, \& Greenberg 1985; Brown 1990; Brown \& Charnley 1990; Hasegawa, Herbst, \& Leung 1992, Hasegawa \& Herbst 1993a, 1993b; Caselli, Hasegawa, \& Herbst 1993; Willacy \& Williams 1993; Shalabiea \& Greenberg 1994). In the rate equation approach, time derivatives of concentrations of species on grains are set equal to the sums of rates of formation and destruction reactions plus adsorption and desorption terms. The calculated abundances of species are averages, which are exact only in the limit in which large numbers of reactive species are present on each grain. Since this is distinctly not the case under most interstellar conditions, the method suffers from a basic theoretical problem. Unlike the Monte Carlo approach, however, the rate equation technique is easily implemented in time-dependent chemical models, since stiff, simultaneous differential equations are treatable. Indeed, in all of the aforementioned studies, it has been possible to follow the chemical evolution 
of both the gas and solid species simultaneously along with their interactions such as accretion, desorption, and/or photoprocessing in the icy grain mantles. Since it is essential for understanding the chemistry of a wide range of interstellar phenomena from diffuse interstellar clouds to protostellar formation to use time-dependent models, the rate equation approach would appear to be an essential method in spite of its theoretical limitations. Thus, until the mid1990s, it was used despite its shortcomings.

Arguing against this usage, A. G. G. M. Tielens (1995, unpublished), in a talk at a conference on interstellar chemistry, showed that for a simple model of grain chemistry involving a limited number of reactants, the rate equation technique fails to reproduce the exact results of a Monte Carlo procedure, mainly for hydrogen-poor conditions (see also Charnley et al. 1997; Tielens \& Charnley 1997). This assertion appears to have slowed down, if not stopped completely, the use of the rate equation method. Recently, however, Caselli et al. (1998) duplicated the work of Tielens and suggested several modifications to the rate equation approach that brought its results into very good agreement with those of the Monte Carlo approach for some simple systems at temperatures of $10 \mathrm{~K}$ and slightly above. The modifications range from several that are theoretically justified to one that is empirical in nature. At this stage, the modifications cannot be applied to grains warmer than $\approx 20 \mathrm{~K}$.

The specific shortcomings of the rate equation procedure shown by A. G. G. M. Tielens (1995, unpublished) and confirmed by Caselli et al. (1998) are that for several simple systems consisting only of atomic $\mathrm{H}$ and atomic $\mathrm{O}$ and/or $\mathrm{N}$ in the gas and producing molecules such as $\mathrm{H}_{2}, \mathrm{O}_{2}, \mathrm{~N}_{2}$, $\mathrm{OH}, \mathrm{H}_{2} \mathrm{O}, \mathrm{NH}_{3}$, and $\mathrm{NO}$ on $10 \mathrm{~K}$ granular surfaces, the unmodified rate equation method overestimates the reaction efficiency of rapidly moving $\mathrm{H}$ atoms in forming hydrogenated species such as $\mathrm{H}_{2}, \mathrm{NH}_{3}$ and $\mathrm{H}_{2} \mathrm{O}$ by a large factor for hydrogen-poor conditions. Yet it is far from clear that this problem will persist in more complex time-dependent models of interstellar clouds. Indeed, the time-independent results of Tielens \& Hagen (1982) using the Monte Carlo approach appear to be adequately reproduced by the results of Hasegawa et al. (1992), in which the rate equation technique was employed. The same preliminary results have been obtained by Shalabiea, Herbst, \& Caselli (1997). It is therefore important to determine the effect of the modifications proposed by Caselli et al. (1998) on realistic gasgrain models.

In this paper, we report the application of the modifications of Caselli et al. (1998) to the complex gas/grain models of dark interstellar clouds first studied by Hasegawa, Herbst, \& Leung (1992) and Hasegawa \& Herbst (1993a, 1993b). Since our purpose here is not to discuss the results of the past and current models in detail, we limit ourselves to discussing the differences between models based on the modified rate equations and those based on the unmodified rate equations. Readers interested in learning about the details of the chemical evolution of gaseous and granular species in dark interstellar clouds as functions of assumptions such as desorption rates and uncertain activation energies are encouraged to read the Hasegawa \& Herbst (1993a, 1993b) articles as well as the earlier Hasegawa et al. (1992) article.

This paper is organized as follows: in $\S 2$ we review the suggested modifications by Caselli et al. (1998) to the rate equation approach. The chemical models and the initial conditions used here are presented in $\S 3$, while $\S 4$ consists of the results and a discussion of them. In $\S 5$ the main conclusions are given.

\section{MODIFICATIONS TO THE RATE EQUATION APPROACH}

In a rate equation treatment without modification, the surface concentrations $n_{s}(i)$ of species $i$ on grains are determined by differential equations of the type

$$
\begin{aligned}
d n_{s}(i) / d t= & \sum_{l} \sum_{j} k_{l j} n_{s}(l) n_{s}(j)-n_{s}(i) \sum_{j} k_{i j} n_{\mathrm{s}}(j) \\
& +k_{\mathrm{acc}}(i) n(i)-\left[k_{\mathrm{evap}}(i)+k_{\mathrm{crd}}(i)\right] n_{s}(i)
\end{aligned}
$$

(Hasegawa, Herbst, \& Leung 1992; Hasegawa \& Herbst 1993a), where $n(i)$ is the gas-phase concentration of species $i$, the $k_{l j}$ are rate coefficients $\left(\mathrm{cm}^{3} \mathrm{~s}^{-1}\right)$ for surface diffusion via thermal hopping or quantum tunneling for species $l$ and $j$, $k_{\text {acc }}(i)$ is the grain accretion rate for species $i$-defined as the grain cross section multiplied by the thermal velocity of gas-phase $i$ and by the number density of the grains - $k_{\text {evap }}(i)$ is the thermal evaporation rate for species $i$, and $k_{\mathrm{crd}}(i)$ is the cosmic-ray-induced, nonthermal desorption rate for species $i$. An alternative formulation to equation (1), favored by Caselli et al. (1998), is to replace the concentrations of grain species $n_{s}(i)$ by actual numbers of atoms and molecules per grain, $N_{s}(i)$. With the latter formulation, the rate coefficients $k_{l j}$ are replaced by simple sums of inverse diffusion times $t_{s}^{-1}$ for sweeping over entire grains; viz.,

$$
k_{l j} \rightarrow k_{L J}=t_{s}^{-1}(L)+t_{s}^{-1}(J),
$$

where $L$ and $J$ are surface species.

The modifications proposed by Caselli et al. (1998) are all changes to assorted rate coefficients $k_{L J}\left(\mathrm{~s}^{-1}\right)$. The first modification concerns the reaction efficiency of $\mathrm{H}$ atoms with heavier, relatively immobile but reactive species. Essentially, the reaction efficiency is reduced to at most unity by replacing the diffusion rate of $\mathrm{H}$ in equation (2) by the greater of the inverse evaporation and accretion times, where the latter is defined by the equation

$$
t_{\mathrm{acc}}^{-1}(\mathrm{H})=k_{\mathrm{acc}}(\mathrm{H}) n(\mathrm{H}) \text {. }
$$

This reduction has the effect of reducing the $\mathrm{H}$ atom reaction efficiency, which was overestimated. Caselli et al. (1998) define a parameter $x$ by the equation

$$
x=t_{\text {evap }}^{-1}(\mathrm{H}) / t_{\text {acc }}^{-1}(\mathrm{H}) .
$$

For $x \geq 1, t_{s}^{-1}(\mathrm{H})$ is replaced by the inverse evaporation time $t_{\text {evap }}^{-1}(\mathrm{H})$, whereas for $x<1$, it is replaced by the inverse accretion time $t_{\mathrm{acc}}^{-1}(\mathrm{H})$. Once corrections are made to such rapid reactions, they are also made to reactions involving $\mathrm{H}$ that are slow because of activation energy, such as $\mathrm{H}+\mathrm{CO}$, so that the relative rates of all $\mathrm{H}$ reactions remain the same: a condition for reproducing the results of the Monte Carlo method.

In their second modification, Caselli et al.(1998) strongly altered the rate coefficient for $\mathrm{H}_{2}$ formation, in the limit that $x \geq 1$, to the following:

$$
k_{\mathrm{H}, \mathrm{H}}^{\prime}=k_{\mathrm{H}, \mathrm{H}} x \exp (-x) .
$$

The modification to the $\mathrm{H}_{2}$ formation rate adjusts for the fact that one $\mathrm{H}$ atom can evaporate before another lands on the same grain. A third (minor) modification corrects for an apparent overly strong reduction in the rate of hydrogenation induced by the first correction when $x \geq 1$. This is 
shown below for the specific case of the reaction between $\mathrm{H}$ and $\mathrm{O}$ :

$$
k_{\mathrm{H}, \mathrm{O}}^{\prime}=k_{\mathrm{H}, \mathrm{O}}+k_{\mathrm{H}, \mathrm{O}}\left[\frac{t_{\mathrm{acc}}^{-1}(\mathrm{O})}{t_{\mathrm{acc}}^{-1}(\mathrm{H})}\right] .
$$

This modification is empirical in nature, and its importance should be tested separately from the others. In the results to be presented here, it was found to be unimportant and was subsequently removed.

In addition to these modifications, there is an additional modification provided for the case of reactions involving heavy surface species and $\mathrm{H}_{2}$, when the activation energy is low but nonnegligible. For more details see Caselli et al. (1998) and Shalabiea et al. (1997). We note that the reactions of these species are not treatable by Monte Carlo methods unless rate equations are used as well.

\section{MODELS AND INITIAL CONDITIONS}

In order to see the effect of the modifications on realistic models of gas-grain interstellar chemistry, we have run two sets of models: models without rate modifications (hereafter unmodified models, or UMs) and models with modifications (hereafter modified models, or MMs). For each class of model, we adopted two forms for the initial hydrogen abundance, designated cases A and B, respectively. Case A models are those for which the hydrogen is initially mainly in molecular form, while case B models are those for which the hydrogen is initially mainly in atomic form. Most gasphase models utilize $\mathrm{H}_{2}$ as the initial form of hydrogen, since this easily shielded species is probably formed earlier in the cloud evolution. Utilizing atomic $\mathrm{H}$ as the initial form of hydrogen means that one is using a diffuse cloud environment at a dense cloud density, since the fixed total hydrogen number density in our models, $n_{\mathrm{H}}=n(\mathrm{H})+2 n\left(\mathrm{H}_{2}\right)$, is $2 \times$ $10^{4} \mathrm{~cm}^{-3}$, a number representative of dense clouds. Although the differences between gas-phase models with hydrogen initially in atomic and molecular form are moderate at early time and nil at steady state, gas-grain models can be heavily dependent on the initial form of hydrogen, since atomic $\mathrm{H}$ is so important in hydrogenations on grain surfaces. (The point is further discussed in $\S 4$.)

In addition to the fixed number density of $2 \times 10^{4} \mathrm{~cm}^{-3}$ for hydrogen, we have used a temperature of $10 \mathrm{~K}$ and a visual extinction $A_{V}=10 \mathrm{mag}$ in our models. For the other elemental abundances we have used the standard "lowmetal" abundances (Lee, Bettens, \& Herbst 1996) listed with the initial forms of the elements in Table 1 . The cosmic-ray ionization rate $\zeta$ has been set equal to the stan-

TABLE 1

Inttial ("Low Metal”) Fractional Abundances WITH RESPECT TO TOTAL HyDROGEN

\begin{tabular}{|c|c|}
\hline Element (Initial Form) & Fractional Abundance \\
\hline $\mathrm{He}$ & $1.4 \mathrm{E}-1$ \\
\hline N.... & $2.14 \mathrm{E}-5$ \\
\hline O.. & $1.76 \mathrm{E}-4$ \\
\hline $\mathrm{C}^{+}$ & $7.3 \mathrm{E}-5$ \\
\hline $\mathrm{S}^{+}$ & $8.0 \mathrm{E}-8$ \\
\hline $\mathrm{Si}^{+}$ & $8.0 \mathrm{E}-9$ \\
\hline $\mathrm{Fe}^{+}$. & $3.0 \mathrm{E}-9$ \\
\hline $\mathrm{Na}^{+} .$. & $2.0 \mathrm{E}-9$ \\
\hline $\mathrm{Mg}^{+} \ldots \ldots \ldots \ldots \ldots \ldots$ & $7.0 \mathrm{E}-9$ \\
\hline $\mathrm{P}^{+} \ldots$ & $3.0 \mathrm{E}-9$ \\
\hline $\mathrm{Cl}^{+}$ & $4.0 \mathrm{E}-9$ \\
\hline
\end{tabular}

dard value of $1.3 \times 10^{-17} \mathrm{~s}^{-1}$. Unlike purely gas-phase models, gas-grain models do not necessarily reach steady state conditions. Our models, based on the earlier calculations of Hasegawa et al. (1992) and Hasegawa \& Herbst (1993a, 1993b), are best divided into "early," "moderate," and "late" times. At early times, little depletion of gaseous material onto the grains has occurred, while at moderate times, a significant amount of depletion has occurred. At late times, much of the gas phase has been lost to the grain mantles, although abundances of some heavy species in the gas are maintained, since we include cosmic-ray-induced desorption (Hasegawa \& Herbst 1993a).

Our gas-grain network of reactions has been mainly constructed by combining the so-called new standard (gasphase) model of Bettens, Lee, \& Herbst (1995) with the grain-surface reactions of Hasegawa \& Herbst (1993a). Compared with the gas-phase network used by Hasegawa \& Herbst (1993a, 1993b), our gas-phase reaction network has been updated to include many new reactions, 133 new gaseous species, and two new elements - chlorine and phosphorus. This inclusion does not strongly affect the grain surface chemistry. Our enhanced gas-grain network, which contains 656 species and 4742 reactions, does not include any of the rapid gas-phase neutral-neutral reactions considered by Bettens, Lee, \& Herbst (1995). The role for such reactions in gas-grain models will be explored in future studies.

One aspect of grain chemistry, discussed by both Hasegawa et al. (1992) and Hasegawa \& Herbst (1993a), is the synthesis of complex molecules on grains. Complex molecule synthesis on grains occurs by relatively heavy reactive species sticking to one another; these processes compete with hydrogenation, which converts reactive heavy radicals into stable hydrogenated products. In their paper, Hasegawa et al. (1992) found that complex molecules could be synthesized on grains at timescales comparable to gasphase syntheses if the initial form of hydrogen is $\mathrm{H}_{2}$, but this conclusion was weakened in the later paper of Hasegawa \& Herbst (1993a), who found that the addition of relatively slow reactions involving surface molecular hydrogen of the type

$$
\mathrm{C}_{n}+\mathrm{H}_{2} \rightarrow \mathrm{C}_{n} \mathrm{H}+\mathrm{H}
$$

and

$$
\mathrm{C}_{n} \mathrm{H}+\mathrm{H}_{2} \rightarrow \mathrm{C}_{n} \mathrm{H}_{2}+\mathrm{H},
$$

where $2 \leq n \leq 9$, is sufficient to choke off complex molecule synthesis on grains if a representative activation energy of $2100 \mathrm{~K}$ is utilized. If, however, a higher activation energy of $4200 \mathrm{~K}$ is used, the conclusions of Hasegawa et al. (1992) stand. The comparison is complicated by the fact that complex molecules are formed in the gas in both models, and then they adsorb onto the grains. Unless specifically noted, the higher activation energy is used here, although some calculations have been run with the lower value. In all calculations, complex molecules do not represent major species on grain mantles.

\section{RESULTS AND DISCUSSION}

The differing time dependence of gaseous atomic $\mathrm{H}$ in cases A and B of our MMs is displayed in Figure 1. In case A (initially $\mathrm{H}_{2}$ dominant) the gaseous atomic hydrogen remains at a concentration of $\approx 1-3 \mathrm{~cm}^{-3}$, while in case $B$ 


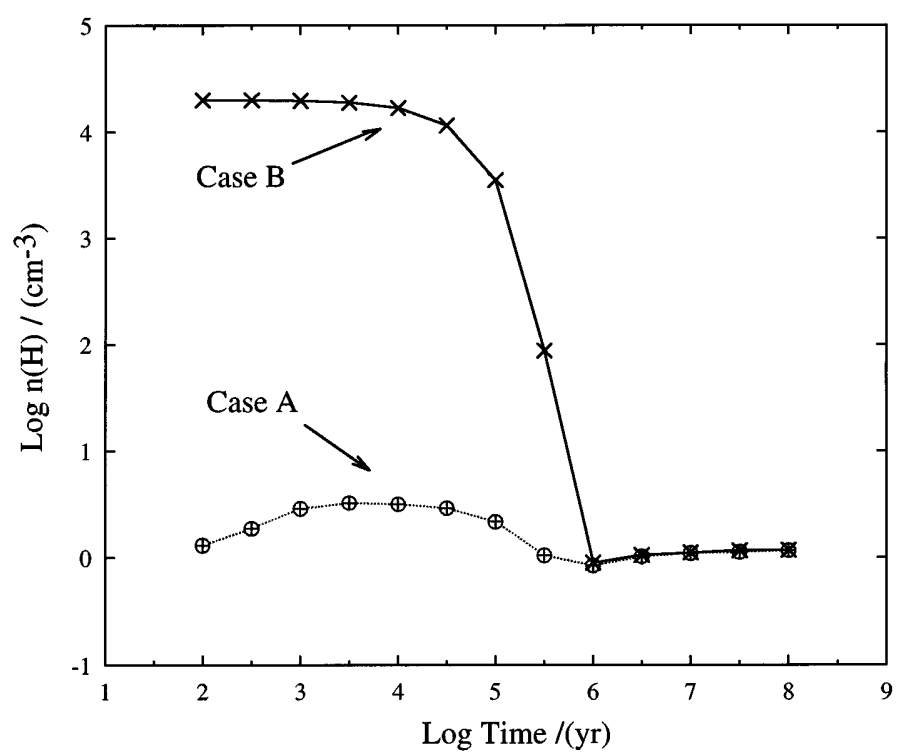

Fig. 1.-Atomic hydrogen gaseous abundance $\left(\mathrm{cm}^{-3}\right)$ in the MMs, plotted against the cloud evolutionary time for the two cases of initial atomic hydrogen abundances: case A, in which the initial form is predominantly molecular, and case $\mathrm{B}$, in which the initial form is predominantly atomic.

(initially $\mathrm{H}$ dominant) the concentration remains high for $\approx 10^{4} \mathrm{yr}$ and then descends rapidly in such a way that after $10^{6} \mathrm{yr}$ the $\mathrm{H}$ atomic abundance is the same in both cases. This point is crucial to the distinction in the surface chemistry between the two cases. In Figure 2, the parameter $x$ (see eq. [4]), equal to the evaporation rate of $\mathrm{H}$ from grains divided by the accretion rate of $\mathrm{H}$ onto grains, is plotted versus time. For case A, the value of $x$ is large at all times, since the accretion rate is low, whereas for case $\mathrm{B}$, the accretion rate for $\mathrm{H}$ is initially quite high so that $x$ is initially low. For large $x, x \exp (-x)$ is essentially zero so that there is no $\mathrm{H}_{2}$ formation from two $\mathrm{H}$ atoms in our MMs (see eq.

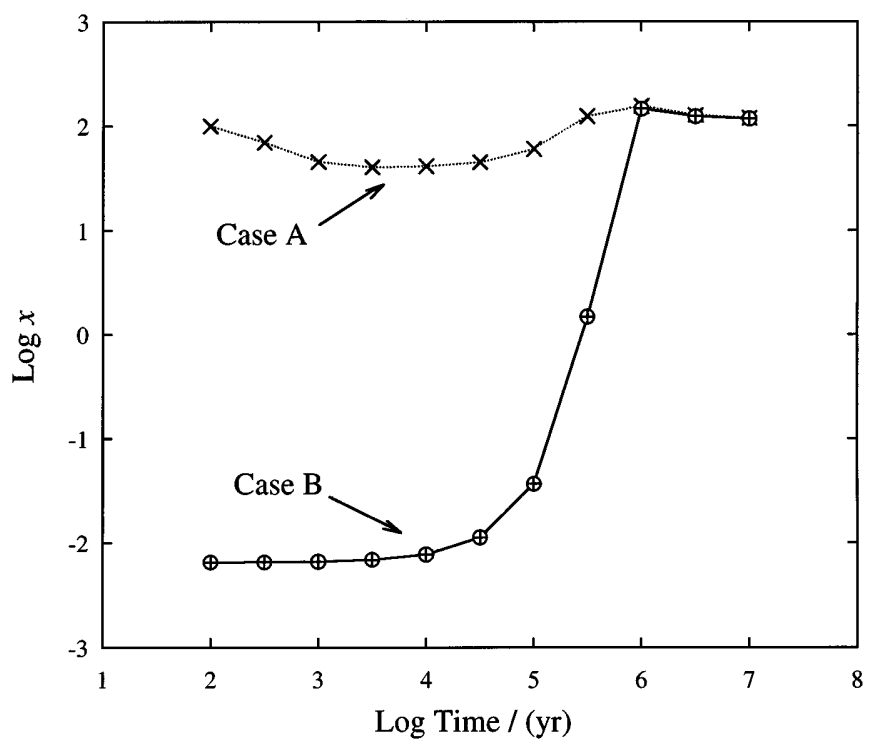

FIG. 2.-Parameter $x$ in the MMs, defined as the ratio of the inverse evaporation time for surface $\mathrm{H}$ to the inverse accretion time of gaseous $\mathrm{H}$ (see eq. [4]), plotted against the cloud evolutionary time for the two cases of initial atomic hydrogen abundances: case A, in which the initial form is predominantly molecular, and case $\mathrm{B}$, in which the initial form is predominantly atomic.
[5]) and $\mathrm{H}_{2}$ can only be generated by reactions such as

$$
\mathrm{H}+\mathrm{HX} \rightarrow \mathrm{H}_{2}+\mathrm{X} .
$$

Also important in understanding the results are the relative gas-phase abundances of a reactive heavy atom such as oxygen and atomic hydrogen; the gas-phase abundances of these species are plotted against time in Figure 3 for case A (initially $\mathrm{H}_{2}$ dominant). The reason for the importance of the comparison is that Caselli et al. (1998) found in their simple models that the unmodified rate equation approach is worst when the gas-phase $\mathrm{O}$ abundance is equal to or greater than 0.1 times the gas-phase $\mathrm{H}$ abundance. Under these conditions, the more rapid diffusive rate of adsorbed atomic $\mathrm{H}$ prevents the formation of nonhydrogenic species such as $\mathrm{O}_{2}$, whereas they are formed efficiently in the "accretion" limit. When gas-phase $\mathrm{H}$ is dominant, on the other hand, it is difficult to form nonhydrogenic species in either the "accretion" limit or the "reactive" limit. Although both $\mathrm{O}$ and $\mathrm{H}$ start off with appreciable (and reasonably similar) abundances, as time progresses, gasphase atomic $\mathrm{O}$ begins to disappear and at late times there is much more $\mathrm{H}$ in the gas than O. Despite the much greater complexity of our current models, in which there are several heavy reactive atoms to be considered, we expect that there should be less difference between the case A MM and UM models at late times. Indeed, one can see that hydrogenation starts to dominate the grain surface chemistry at times of about $10^{6} \mathrm{yr}$ and higher. At these times, the modifications involving $\mathrm{H}$ atom surface reactions are of little importance, because the lowered rate coefficients are matched by an increase in the surface $\mathrm{H}$ concentration. At early times, however, we expect that the modifications may lead to substantial changes, generally in the direction toward less hydrogenation. As opposed to these case A distinctions, we expect smaller to negligible differences between the MM and UM results with case B. This expectation is in general borne out by our calculations, and we do not report the case B results in as much detail.

To illustrate the differences between the UM and MM models in case A, our case A results for both models versus

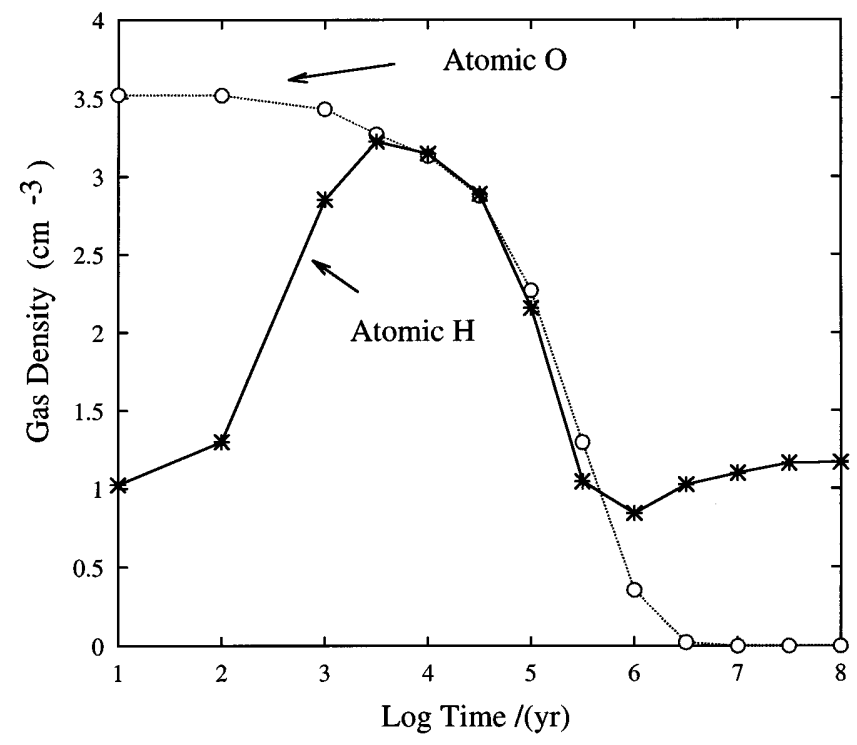

Fig. 3.-Gaseous atomic $\mathrm{H}$ and $\mathrm{O}$ abundances $\left(\mathrm{cm}^{-3}\right)$ in our $\mathrm{MM} \mathrm{A}$, plotted against the evolutionary time. 

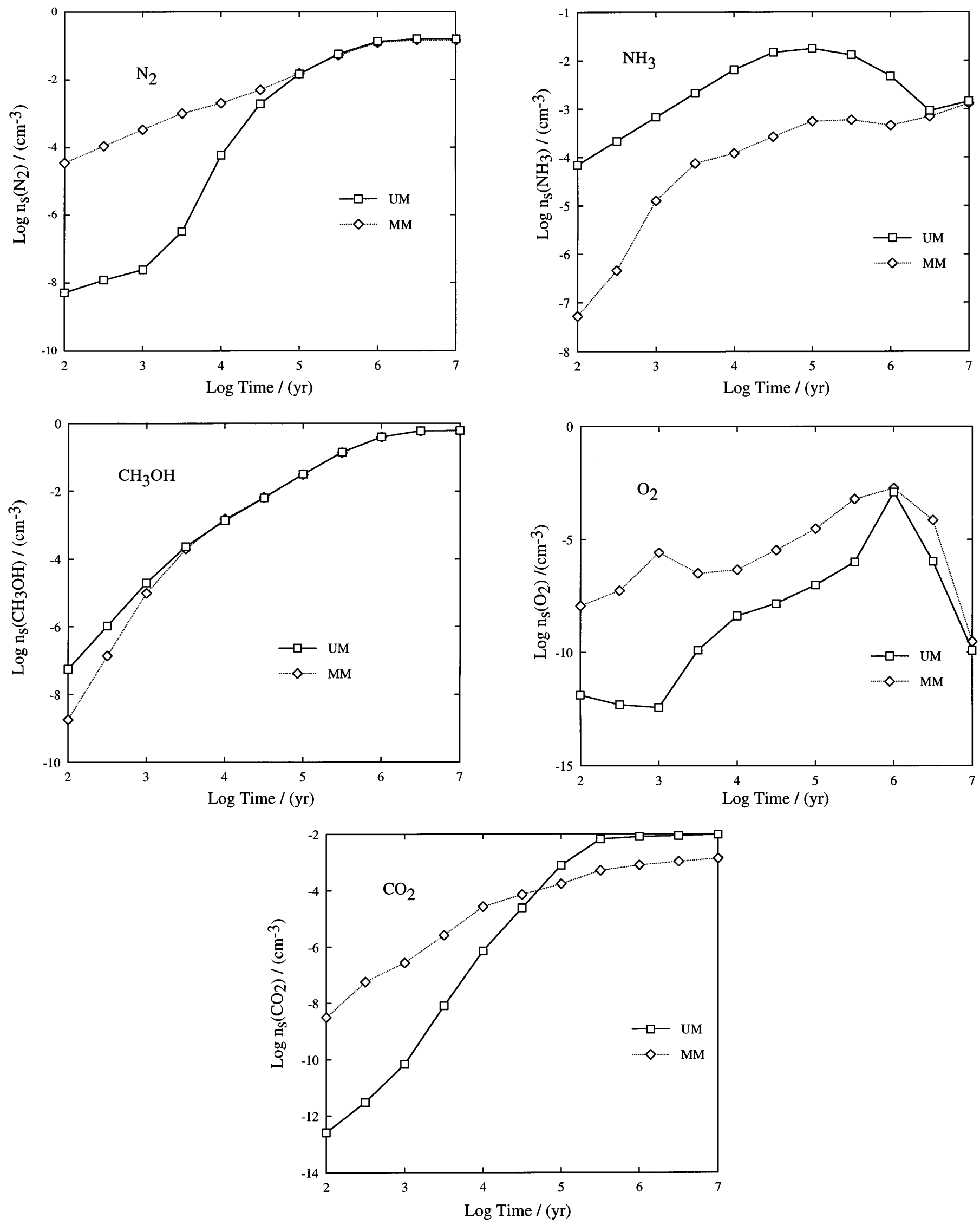

Fig. 4.-Temporal evolution of the surface abundance $\left(\mathrm{cm}^{-3}\right)$ of some of the key grain mantle species for the modified model (MM) and the unmodified model (UM), plotted using case $A$, in which $\mathrm{H}_{2}$ is the initial form of hydrogen. 
evolutionary time are shown in Figures $4 a-4 e$ for the grain concentrations of a number of key solid-phase species: specifically, $\mathrm{N}_{2}, \mathrm{NH}_{3}, \mathrm{CH}_{3} \mathrm{OH}, \mathrm{O}_{2}$, and $\mathrm{CO}_{2}$, respectively. The concentrations are expressed in units of $\mathrm{cm}^{-3}$; if one assumes the grain concentration to be $10^{-12} \times n_{\mathrm{H}}$, the concentrations can be converted to numbers of species per grain by division by this product. As expected, for most of these species, the differences between the UM and MM models get smaller or disappear with time on about the same timescale that gaseous atomic $\mathrm{H}$ begins to dominate over gaseous atomic $\mathrm{O}$. Looking at the hydrogenless species $\mathrm{N}_{2}$ and $\mathrm{O}_{2}$, one sees that, at early times, the abundances of these species on grains are significantly greater with the $\mathrm{MM}$, since the rate of grain hydrogenation with $\mathrm{H}$ atoms is slowed. But, as time evolves and the accretion rate of heavy atoms decreases, the modified and unmodified results become identical for $\mathrm{N}_{2}$ and similar for $\mathrm{O}_{2}$. Note that surface $\mathrm{O}_{2}$ differs from surface $\mathrm{N}_{2}$ because it is chemically destroyed at late times (Hasegawa et al. 1992). Surface $\mathrm{CO}_{2}$ presents a more complicated case. Although, as expected, the calculated surface abundance of $\mathrm{CO}_{2}$ in the $\mathrm{MM}$ exceeds that in the UM for times less than $\approx 10^{5} \mathrm{yr}$, at times later than these the modified results actually dip below the unmodified ones. Detailed analysis shows this unexpected behavior to be due to the depletion of surface atomic oxygen in the MM case by reaction with surface $\mathrm{O}_{2}$; the surface $\mathrm{O}$ is needed to produce $\mathrm{CO}_{2}$ via the reaction

$$
\mathrm{O}+\mathrm{HCO} \rightarrow \mathrm{CO}_{2}+\mathrm{H} .
$$

The hydrogenated surface species $\mathrm{NH}_{3}$ and $\mathrm{CH}_{3} \mathrm{OH}$ also show varying behavior. For hydrogenated species, we expect the modified surface concentrations to be lower than the unmodified ones initially, since more unsaturated species are produced using the modified rates. This effect is indeed seen for $\mathrm{NH}_{3}$ and $\mathrm{CH}_{3} \mathrm{OH}$, although for the latter it is a minute effect that disappears after $\approx 10^{3} \mathrm{yr}$, while for the former it is a large effect that takes more than $10^{6} \mathrm{yr}$ to disappear. The differences no doubt are at least partially related to the competitive reactions that limit the efficiency of the hydrogenations $\mathrm{N} \rightarrow \mathrm{NH}_{3}$ and $\mathrm{CO} \rightarrow \mathrm{CH}_{3} \mathrm{OH}$. One must remember in considering these differences that we are dealing with complex gas-grain networks in which many processes are occurring simultaneously. Still, the expected time behavior of both unsaturated and saturated surface species is qualitatively in agreement with a simple generalization of earlier results on simple systems.

In Table 2, we have listed the case A surface abundances $\left(\mathrm{cm}^{-3}\right)$ calculated in both the UM and MM models for major surface species at times ranging from $10^{2}-10^{7} \mathrm{yr}$. The tabulated results confirm the general expectation that differences tend to go away as time increases. By the "late time" of $10^{7} \mathrm{yr}$, the only major species showing any significant difference between the UM and MM results is $\mathrm{CO}_{2}$, for which the abundance in the MM is lower by a factor of 6-7. A decade earlier in time, the only other major species showing a significant distinction between the two models is ammonia. At a time of $10^{5} \mathrm{yr}$, some more serious (order-ofmagnitude) differences appear, while at times earlier than these, the differences are major. In addition to the dominant surface species shown in Table 2, we have also listed the surface abundances of a few complex molecules, both relatively hydrogen poor and hydrogen rich. The differences in the computed abundances for these species are also minimal for times greater than $10^{6} \mathrm{yr}$. At earlier times there is generally an increase in concentration with the MM, presumably due to the slower hydrogenation, which allows reactive heavy species to come together before hydrogenation renders them unreactive.

In Table 3, we compare the results of all eight of our model calculations (case A, case B; UM, MM; activation energy $E_{a}=2100 \mathrm{~K}, 4200 \mathrm{~K}$ ) for the main components of grain mantles as well as a few complex surface species at a late evolutionary time of $10^{7} \mathrm{yr}$. For the modified case A models, the use of the low and high activation energies for the reaction types in equations (7) and (8) results in no discernible differences. Only very limited differences, within a factor of 2, exist for the "representative" complex species- $\mathrm{HC}_{3} \mathrm{~N}, \mathrm{H}_{3} \mathrm{C}_{3} \mathrm{~N}$, and $\mathrm{H}_{3} \mathrm{C}_{9} \mathrm{~N}$-for the unmodified case A models. For the case $\mathrm{B}$ models, we reach the same conclusion, except for $\mathrm{H}_{3} \mathrm{C}_{9} \mathrm{~N}$ in the UM, where the abundance is greater by a factor of 20 when the higher activation energy is used. However, as can be seen in Table 3, some large differences exist between the case A and case B models, and these are concentrated in the complex species. Although a simple analysis would suggest that complex surface molecules be more abundant for case A, because of the relative paucity of atomic hydrogen for much of the cloud evolution, this is only obviously true for $\mathrm{H}_{3} \mathrm{C}_{9} \mathrm{~N}$, a

TABLE 2

Absolute Case A Abundances $\left(\mathrm{cm}^{-3}\right)$ for Selected Solid Species

\begin{tabular}{|c|c|c|c|c|c|c|c|c|}
\hline \multirow[b]{2}{*}{ SPECIES } & \multicolumn{2}{|c|}{$10^{2}$} & \multicolumn{2}{|c|}{$10^{5}$} & \multicolumn{2}{|c|}{$10^{6}$} & \multicolumn{2}{|c|}{$10^{7}$} \\
\hline & UM & MM & UM & MM & UM & MM & UM & MM \\
\hline $\mathrm{N}_{2}$ & $5.1 \mathrm{E}-09$ & $3.4 \mathrm{E}-05$ & $1.5 \mathrm{E}-02$ & $1.5 \mathrm{E}-02$ & $1.3 \mathrm{E}-01$ & $1.2 \mathrm{E}-01$ & $1.5 \mathrm{E}-01$ & $1.4 \mathrm{E}-01$ \\
\hline $\mathrm{O}_{2}$. & $1.3 \mathrm{E}-12$ & $1.1 \mathrm{E}-08$ & $9.6 \mathrm{E}-08$ & $3.0 \mathrm{E}-05$ & $1.3 \mathrm{E}-03$ & $1.9 \mathrm{E}-03$ & $1.2 \mathrm{E}-10$ & $3.0 \mathrm{E}-10$ \\
\hline $\mathrm{CO}$ & $1.3 \mathrm{E}-09$ & $1.1 \mathrm{E}-07$ & $2.0 \mathrm{E}-04$ & $5.0 \mathrm{E}-04$ & $2.3 \mathrm{E}-03$ & $1.7 \mathrm{E}-03$ & $3.7 \mathrm{E}-07$ & $1.9 \mathrm{E}-07$ \\
\hline $\mathrm{CO}_{2}$ & $2.5 \mathrm{E}-13$ & $3.1 \mathrm{E}-09$ & $7.6 \mathrm{E}-04$ & $1.7 \mathrm{E}-04$ & $7.9 \mathrm{E}-03$ & $7.7 \mathrm{E}-04$ & $9.5 \mathrm{E}-03$ & $1.4 \mathrm{E}-03$ \\
\hline $\mathrm{H}_{2} \mathrm{O}$. & $5.3 \mathrm{E}-04$ & $4.8 \mathrm{E}-04$ & $4.1 \mathrm{E}-01$ & $4.1 \mathrm{E}-01$ & $1.8 \mathrm{E}-00$ & $1.8 \mathrm{E}-00$ & $2.3 \mathrm{E}-00$ & $2.3 \mathrm{E}-00$ \\
\hline $\mathrm{CH}_{4}$. & $2.5 \mathrm{E}-05$ & $2.4 \mathrm{E}-05$ & $1.2 \mathrm{E}-01$ & $1.0 \mathrm{E}-01$ & $1.6 \mathrm{E}-01$ & $1.5 \mathrm{E}-01$ & $1.4 \mathrm{E}-01$ & $1.4 \mathrm{E}-01$ \\
\hline $\mathrm{NH}_{3}$. & $6.9 \mathrm{E}-05$ & $5.3 \mathrm{E}-08$ & $1.8 \mathrm{E}-02$ & $5.6 \mathrm{E}-04$ & $4.8 \mathrm{E}-03$ & $4.6 \mathrm{E}-04$ & $1.4 \mathrm{E}-03$ & $1.3 \mathrm{E}-03$ \\
\hline $\mathrm{H}_{2} \mathrm{CO} \ldots \ldots \ldots$ & $5.7 \mathrm{E}-08$ & $1.6 \mathrm{E}-08$ & $3.2 \mathrm{E}-02$ & $3.1 \mathrm{E}-02$ & $4.0 \mathrm{E}-01$ & $3.9 \mathrm{E}-01$ & $6.2 \mathrm{E}-01$ & $6.0 \mathrm{E}-01$ \\
\hline $\mathrm{CH}_{3} \mathrm{OH} \ldots \ldots$ & $5.6 \mathrm{E}-08$ & $1.8 \mathrm{E}-09$ & $3.2 \mathrm{E}-02$ & $3.1 \mathrm{E}-02$ & $4.0 \mathrm{E}-01$ & $3.9 \mathrm{E}-01$ & $6.1 \mathrm{E}-01$ & $6.0 \mathrm{E}-01$ \\
\hline $\mathrm{HC}_{3} \mathrm{~N} \ldots \ldots \ldots$ & $1.5 \mathrm{E}-14$ & $3.0 \mathrm{E}-13$ & $4.7 \mathrm{E}-07$ & $2.0 \mathrm{E}-06$ & $1.2 \mathrm{E}-07$ & $6.1 \mathrm{E}-08$ & $1.4 \mathrm{E}-08$ & $9.9 \mathrm{E}-09$ \\
\hline $\mathrm{H}_{3} \stackrel{\mathrm{C}}{3}_{3} \mathrm{~N} \ldots \ldots$ & $7.7 \mathrm{E}-16$ & $1.5 \mathrm{E}-15$ & $2.4 \mathrm{E}-08$ & $1.0 \mathrm{E}-07$ & $6.2 \mathrm{E}-09$ & $3.0 \mathrm{E}-09$ & $7.1 \mathrm{E}-10$ & $4.9 \mathrm{E}-10$ \\
\hline $\mathrm{H}_{3} \mathrm{C}_{9} \mathrm{~N} \ldots \ldots \ldots$ & $2.0 \mathrm{E}-19$ & $1.0 \mathrm{E}-19$ & $3.2 \mathrm{E}-09$ & $2.9 \mathrm{E}-09$ & $6.5 \mathrm{E}-09$ & $5.2 \mathrm{E}-09$ & $7.0 \mathrm{E}-09$ & $5.2 \mathrm{E}-09$ \\
\hline
\end{tabular}

NoTE.-Values are for selected solid species using unmodified models (UM) and modified models (MM) at $10^{2}, 10^{5}, 10^{6}$, and $10^{7} \mathrm{yr}$. The high activation energy $E_{a}=4200 \mathrm{~K}$ is utilized. 
TABLE 3

Absolute Abundances $\left(\mathrm{cm}^{-3}\right)$ for Selected Solid Species

\begin{tabular}{|c|c|c|c|c|c|c|c|c|}
\hline \multirow[b]{3}{*}{ SPECIES } & \multicolumn{4}{|c|}{ CASE A } & \multicolumn{4}{|c|}{ CASE B } \\
\hline & \multicolumn{2}{|c|}{ UM } & \multicolumn{2}{|c|}{ MM } & \multicolumn{2}{|c|}{ UM } & \multicolumn{2}{|c|}{ MM } \\
\hline & $2100 \mathrm{~K}$ & $4200 \mathrm{~K}$ & $2100 \mathrm{~K}$ & $4200 \mathrm{~K}$ & $2100 \mathrm{~K}$ & $4200 \mathrm{~K}$ & $2100 \mathrm{~K}$ & $4200 \mathrm{~K}$ \\
\hline $\mathrm{N}_{2}$ & $1.5 \mathrm{E}-01$ & $1.5 \mathrm{E}-01$ & $1.4 \mathrm{E}-01$ & $1.4 \mathrm{E}-01$ & $1.6 \mathrm{E}-01$ & $1.6 \mathrm{E}-01$ & $1.6 \mathrm{E}-01$ & $1.6 \mathrm{E}-01$ \\
\hline $\mathrm{O}_{2} \ldots$ & $1.2 \mathrm{E}-10$ & $1.2 \mathrm{E}-10$ & $3.0 \mathrm{E}-10$ & $3.0 \mathrm{E}-10$ & $1.5 \mathrm{E}-11$ & $1.5 \mathrm{E}-11$ & $3.3 \mathrm{E}-11$ & $3.3 \mathrm{E}-11$ \\
\hline $\mathrm{CO} \ldots$ & $3.7 \mathrm{E}-07$ & $3.7 \mathrm{E}-07$ & $1.9 \mathrm{E}-07$ & $1.9 \mathrm{E}-07$ & $3.5 \mathrm{E}-07$ & $3.5 \mathrm{E}-07$ & $2.0 \mathrm{E}-07$ & $2.0 \mathrm{E}-07$ \\
\hline $\mathrm{CO}_{2}$ & $9.5 \mathrm{E}-03$ & $9.5 \mathrm{E}-03$ & $1.4 \mathrm{E}-03$ & $1.4 \mathrm{E}-03$ & $4.5 \mathrm{E}-03$ & $4.5 \mathrm{E}-03$ & $1.9 \mathrm{E}-03$ & $1.9 \mathrm{E}-03$ \\
\hline $\mathrm{H}_{2} \mathrm{O} \ldots$ & $2.3 \mathrm{E}-00$ & $2.3 \mathrm{E}-00$ & $2.3 \mathrm{E}-00$ & $2.3 \mathrm{E}-00$ & $2.3 \mathrm{E}-00$ & $2.3 \mathrm{E}-00$ & $2.4 \mathrm{E}-00$ & $2.4 \mathrm{E}-00$ \\
\hline $\mathrm{CH}_{4}$. & $1.4 \mathrm{E}-01$ & $1.4 \mathrm{E}-01$ & $1.4 \mathrm{E}-01$ & $1.4 \mathrm{E}-01$ & $2.2 \mathrm{E}-01$ & $2.2 \mathrm{E}-01$ & $2.4 \mathrm{E}-01$ & $2.4 \mathrm{E}-01$ \\
\hline $\mathrm{NH}_{3}$. & $1.4 \mathrm{E}-03$ & $1.4 \mathrm{E}-03$ & $1.3 \mathrm{E}-03$ & $1.3 E-03$ & $1.4 \mathrm{E}-03$ & $1.4 \mathrm{E}-03$ & $1.4 \mathrm{E}-03$ & $1.4 \mathrm{E}-03$ \\
\hline $\mathrm{H}_{2} \mathrm{CO} \ldots \ldots$ & $6.2 \mathrm{E}-01$ & $6.2 \mathrm{E}-01$ & $6.0 \mathrm{E}-01$ & $6.0 \mathrm{E}-01$ & $5.9 \mathrm{E}-01$ & $5.9 \mathrm{E}-01$ & $5.8 \mathrm{E}-01$ & $5.8 \mathrm{E}-01$ \\
\hline $\mathrm{CH}_{3} \mathrm{OH}$. & $6.1 \mathrm{E}-01$ & $6.1 \mathrm{E}-01$ & $6.0 \mathrm{E}-01$ & $6.0 \mathrm{E}-01$ & $5.9 \mathrm{E}-01$ & $5.9 \mathrm{E}-01$ & $5.7 \mathrm{E}-01$ & $5.7 \mathrm{E}-01$ \\
\hline $\mathrm{HC}_{3} \mathrm{~N} \ldots \ldots \ldots$ & $8.5 \mathrm{E}-09$ & $1.4 \mathrm{E}-08$ & $9.9 \mathrm{E}-09$ & $9.9 \mathrm{E}-09$ & $1.7 \mathrm{E}-08$ & $3.0 \mathrm{E}-08$ & $2.5 \mathrm{E}-08$ & $2.5 \mathrm{E}-08$ \\
\hline $\mathrm{H}_{3} \breve{C}_{3} \mathrm{~N} \ldots \ldots$ & $4.4 \mathrm{E}-10$ & $7.1 \mathrm{E}-10$ & $4.9 \mathrm{E}-10$ & $4.9 \mathrm{E}-10$ & $8.6 \mathrm{E}-10$ & $1.6 \mathrm{E}-09$ & $1.2 \mathrm{E}-09$ & $1.2 \mathrm{E}-09$ \\
\hline $\mathrm{H}_{3} \mathrm{C}_{9} \mathrm{~N} \ldots \ldots \ldots$ & $5.4 \mathrm{E}-09$ & $7.0 \mathrm{E}-09$ & $5.2 \mathrm{E}-09$ & $5.2 \mathrm{E}-09$ & $2.2 \mathrm{E}-11$ & $3.9 \mathrm{E}-10$ & $2.3 \mathrm{E}-11$ & $2.5 \mathrm{E}-11$ \\
\hline
\end{tabular}

NoTE.-Values are for selected solid species using unmodified models (UM) and modified models (MM) at $10^{7} \mathrm{yr}$.

partially hydrogenated version of $\mathrm{HC}_{9} \mathrm{~N}$, suggesting that history is not necessarily the only causative factor.

The extent of complex molecular development for case A models is shown in more detail in Table 4, where we have listed the surface abundances $\left(\mathrm{cm}^{-3}\right)$ at $10^{7} \mathrm{yr}$ for a variety of hydrocarbons and organo-nitrogen compounds, including unsaturated and relatively saturated cyanopolyynes. Unlike the small sample of complex molecules in Table 3, one can see clearly from this table that, for some complex molecular abundances, use of the low and high activation energies for the processes in equations (7) and (8) can lead to pronounced differences whether UMs or MMs are utilized. This behavior is expected, since the lower activation energy leads to more hydrogenation via surface $\mathrm{H}_{2}$, which in turn prevents the growth of large species. This generalization holds best for the hydrocarbons and carbon clusters; for the organo-nitrogen compounds, the MMs tend to show smaller differences between the high- and low- $E_{a}$ cases than do the UMs and tend to yield abundances equal to the lower abundances (obtained with low $E_{a}$ ) of the UMs. Both effects possibly stem from a particular modification of Caselli et al. (1998) that has the effect of enhancing the efficiency of hydrogenation via $\mathrm{H}_{2}$ in the competition with heavy atom/radical reaction.

The dominant forms of complex molecules on old grains are hydrogenated ones, as can be seen from the large $\mathrm{H}_{5} \mathrm{C}_{3} \mathrm{~N}\left(\mathrm{CH}_{3} \mathrm{CH}_{2} \mathrm{CN}\right.$; ethyl cyanide) abundances in Table 4. This point is discussed in more detail in the previous

TABLE 4

Absolute (Case A) Abundances $\left(\mathrm{Cm}^{-3}\right.$ ) for Selected Complex Solid Species

\begin{tabular}{|c|c|c|c|c|}
\hline \multirow[b]{2}{*}{ SPECIES } & \multicolumn{2}{|c|}{ UM } & \multicolumn{2}{|c|}{ MM } \\
\hline & $E_{a}=2100 \mathrm{~K}$ & $E_{a}=4200 \mathrm{~K}$ & $E_{a}=2100 \mathrm{~K}$ & $E_{a}=4200 \mathrm{~K}$ \\
\hline $\mathrm{C}_{2}$ & $2.8 \mathrm{E}-16$ & $1.9 \mathrm{E}-12$ & $3.0 \mathrm{E}-16$ & $2.2 \mathrm{E}-12$ \\
\hline $\mathrm{C}_{2} \mathrm{H}$. & $3.3 \mathrm{E}-16$ & $3.2 \mathrm{E}-12$ & $3.5 \mathrm{E}-16$ & $2.4 \mathrm{E}-12$ \\
\hline$\ldots \ldots$ & $1.6 \mathrm{E}-17$ & $8.6 \mathrm{E}-14$ & $1.8 \mathrm{E}-17$ & $9.8 \mathrm{E}-14$ \\
\hline $\mathrm{C}_{3} \mathrm{H} \ldots \ldots \ldots$ & $1.8 \mathrm{E}-17$ & $9.3 \mathrm{E}-14$ & $1.9 \mathrm{E}-17$ & $1.0 \mathrm{E}-13$ \\
\hline $\mathrm{C}_{4} \ldots \ldots \ldots \ldots$ & $6.1 \mathrm{E}-18$ & $2.8 \mathrm{E}-14$ & $7.0 \mathrm{E}-18$ & $3.3 \mathrm{E}-14$ \\
\hline $\mathrm{C}_{4}^{4} \mathrm{H} \ldots$ & $6.7 \mathrm{E}-18$ & $3.1 \mathrm{E}-14$ & $7.7 \mathrm{E}-18$ & $3.6 \mathrm{E}-14$ \\
\hline $\mathrm{C}_{5} \ldots \ldots \ldots \ldots$ & $4.1 \mathrm{E}-19$ & $1.7 \mathrm{E}-15$ & $4.9 \mathrm{E}-19$ & $2.1 \mathrm{E}-15$ \\
\hline $\mathrm{C}_{5} \mathrm{H} \ldots \ldots \ldots$ & $4.2 \mathrm{E}-19$ & $1.7 \mathrm{E}-15$ & $4.9 \mathrm{E}-19$ & $2.1 \mathrm{E}-15$ \\
\hline $\mathrm{C}_{6} \ldots \ldots \ldots \ldots$ & $1.0 \mathrm{E}-20$ & $4.1 \mathrm{E}-17$ & $1.3 \mathrm{E}-20$ & $5.2 \mathrm{E}-17$ \\
\hline $\mathrm{C}_{6} \mathrm{H} \ldots \ldots \ldots$ & $1.0 \mathrm{E}-20$ & $4.4 \mathrm{E}-17$ & $1.3 \mathrm{E}-20$ & $5.2 \mathrm{E}-17$ \\
\hline $\mathrm{C}_{7} \ldots \ldots \ldots \ldots$ & $3.0 \mathrm{E}-22$ & $1.1 \mathrm{E}-18$ & $3.8 \mathrm{E}-22$ & $1.5 \mathrm{E}-18$ \\
\hline $\mathrm{C}_{7} \mathrm{H}$. & $3.0 \mathrm{E}-22$ & $1.2 \mathrm{E}-18$ & $3.9 \mathrm{E}-22$ & $1.5 \mathrm{E}-18$ \\
\hline $\mathrm{C}_{8} \ldots \ldots \ldots \ldots$ & $1.2 \mathrm{E}-23$ & $4.3 \mathrm{E}-20$ & $1.5 \mathrm{E}-23$ & $5.8 \mathrm{E}-20$ \\
\hline $\mathrm{C}_{8} \mathrm{H} \ldots \ldots \ldots$ & $1.2 \mathrm{E}-23$ & $4.6 \mathrm{E}-20$ & $1.5 \mathrm{E}-23$ & $5.9 \mathrm{E}-20$ \\
\hline $\mathrm{HC}_{3} \mathrm{~N} \ldots \ldots$ & $8.5 \mathrm{E}-09$ & $1.4 \mathrm{E}-08$ & $9.9 \mathrm{E}-09$ & $9.9 \mathrm{E}-09$ \\
\hline $\mathrm{HC}_{3} \mathrm{O} \ldots \ldots$ & $3.2 \mathrm{E}-21$ & $2.9 \mathrm{E}-18$ & $2.8 \mathrm{E}-21$ & $3.7 \mathrm{E}-21$ \\
\hline $\mathrm{HC}_{5} \mathrm{~N} \ldots \ldots$ & $1.8 \mathrm{E}-11$ & $1.2 \mathrm{E}-10$ & $2.1 \mathrm{E}-11$ & $2.2 \mathrm{E}-11$ \\
\hline $\mathrm{HC}_{7} \mathrm{~N} \ldots \ldots$ & $8.7 \mathrm{E}-15$ & $8.2 \mathrm{E}-14$ & $1.1 \mathrm{E}-14$ & $1.2 \mathrm{E}-14$ \\
\hline $\mathrm{HC}_{9} \mathrm{~N} \ldots \ldots$ & $4.4 \mathrm{E}-18$ & $1.4 \mathrm{E}-16$ & $5.4 \mathrm{E}-18$ & $9.8 \mathrm{E}-18$ \\
\hline $\mathrm{H}_{2} \mathrm{C}_{5} \mathrm{~N} \ldots \ldots$ & $1.5 \mathrm{E}-17$ & $1.0 \mathrm{E}-16$ & $1.5 \mathrm{E}-17$ & $1.6 \mathrm{E}-17$ \\
\hline $\mathrm{H}_{2} \mathrm{C}_{7} \mathrm{~N} \ldots \ldots$ & $6.9 \mathrm{E}-21$ & $6.4 \mathrm{E}-20$ & $7.9 \mathrm{E}-21$ & $8.9 \mathrm{E}-21$ \\
\hline $\mathrm{H}_{2} \mathrm{C}_{9} \mathrm{~N} \ldots \ldots$ & $3.4 \mathrm{E}-24$ & $1.1 \mathrm{E}-22$ & $4.0 \mathrm{E}-24$ & $7.2 \mathrm{E}-24$ \\
\hline $\mathrm{H}_{3} \mathrm{C}_{5} \mathrm{~N} \ldots \ldots$ & $4.2 \mathrm{E}-06$ & $7.0 \mathrm{E}-06$ & $4.0 \mathrm{E}-06$ & $4.0 \mathrm{E}-06$ \\
\hline $\mathrm{H}_{3} \mathrm{C}_{7} \mathrm{~N} \ldots \ldots$ & $1.5 \mathrm{E}-07$ & $1.8 \mathrm{E}-07$ & $1.4 \mathrm{E}-07$ & $1.4 \mathrm{E}-07$ \\
\hline $\mathrm{H}_{3} \mathrm{C}_{9} \mathrm{~N} \ldots \ldots$ & $5.4 \mathrm{E}-09$ & $7.0 \mathrm{E}-09$ & $5.2 \mathrm{E}-09$ & $5.2 \mathrm{E}-09$ \\
\hline $\mathrm{H}_{4} \mathrm{C}_{3} \mathrm{~N} \ldots \ldots$ & $7.2 \mathrm{E}-15$ & $1.2 \mathrm{E}-14$ & $7.3 \mathrm{E}-15$ & $7.3 \mathrm{E}-15$ \\
\hline $\mathrm{H}_{5} \mathrm{C}_{3} \mathrm{~N} \ldots \ldots$ & $1.4 \mathrm{E}-04$ & $1.7 \mathrm{E}-04$ & $1.3 \mathrm{E}-04$ & $1.3 \mathrm{E}-04$ \\
\hline
\end{tabular}

NoTE.-Values are for some complex solid species at $10^{7} \mathrm{yr}$ with unmodified models (UM) and modified models (MM). 
papers by Hasegawa et al. (1992) and Hasegawa \& Herbst (1993a). A complete list of calculated abundances at all times can be obtained from the authors.

\section{SUMMARY}

A new code has been constructed to apply the modifications to the rate equation approach to gas-grain chemistry suggested and demonstrated for simple models by Caselli et al. (1998). These modifications have been proposed so that the practical rate equation method can yield the same results as the Monte Carlo approach for systems sufficiently simple that the latter approach can be utilized. The code has been used to run a variety of realistic model calculations of dark interstellar clouds with an updated gasgrain network of reactions. The differences between models run with the unmodified rates and those run with the modified rates depend on the initial conditions used. If hydrogen is assumed to start in its atomic form, the differences are, in general, rather minor. If, on the other hand, hydrogen is assumed to start in its molecular form, the differences are significant but show a temporal pattern. In particular, the discrepancies in surface abundances for major surface species are significant mainly at early and intermediate times of cloud evolutions, where the gas phase contains large abundances of heavy species that are reactive when they land on grain surfaces and are often able to react with one another under the modified approach rather than be hydrogenated. At late times, there are small or no differences to be seen between the MMs and the UMs, because atomic $\mathrm{H}$ becomes the only major gas-phase species capable of rapid reaction when it lands on grain surfaces so that hydrogenation is dominant, a condition that for the most part appears to be accurately handled by the unmodified treatment. For a few of the complex molecules possessing low surface abundances, differences in calculated concentrations between the MMs and UMs remain even at late times for models in which $\mathrm{H}_{2}$ is the initial form of hydrogen and the activation energy for hydrogenation of carbon clusters and unsaturated hydrocarbons is relatively high $\left(E_{a}=\right.$ $4200 \mathrm{~K})$.

In summary, the differences in surface abundances obtained with our MMs of dark clouds as compared with our UMs are neither nil nor critical, except perhaps at very early times, where they can be very large. The calculated abundances obtained with unmodified rate equations often show only small changes from the abundances obtained with modified rate equations, especially at late times, which are needed for significant mantles to be built up. This conclusion cannot be generalized to other sets of physical conditions, however, since there is little to no guarantee that the unmodified rate equations work in all complex situations. In addition, even the modified rate equations proposed by Caselli et al. (1998) and utilized here are not general and, at the current time, cannot be used confidently for warm grains.

Since the differences with previous models at late times are not great, some of the problems of those previous models are retained in the new models reported here. For example, it is difficult to match the observed abundance of surface $\mathrm{CO}$ at late times when the models prefer for the $\mathrm{CO}$ to be converted into methanol (Caselli et al. 1994). A large surface abundance of $\mathrm{CO}$ can be maintained at earlier periods as long as hydrogenation is rather slow, because of a small abundance of $\mathrm{H}$ and, in addition, a significant gas- phase $\mathrm{CO}$ to replenish the loss of surface $\mathrm{CO}$ to hydrogenation. For example, in a previous model calculation (Caselli et al. 1994), we showed that even with the unmodified rates a large surface abundance of $\mathrm{CO}$ could be maintained until late times if the surface abundance of $\mathrm{H}$ atoms were reduced catalytically by the use of "high metal" abundances containing a significant amount of sulfur.

Using a steady state Monte Carlo method, Tielens \& Whittet (1997) demonstrated a large abundance of surface $\mathrm{CO}$ in a system rich in gaseous $\mathrm{CO}$ and poor in atomic hydrogen. Such low-H fractional abundances are associated with higher gas densities than we have chosen. Their result is easily duplicated with rate equations. Using either unmodified or modified rates, a simple argument in the spirit of Caselli et al. (1998) considering only gaseous $\mathrm{H}$ and $\mathrm{CO}$ shows that the ratio of the surface abundance of $\mathrm{CO}$ to that of the hydrogenated forms of $\mathrm{CO}$ (including $\mathrm{HCO}$, $\mathrm{H}_{2} \mathrm{CO}$, and $\mathrm{CH}_{3} \mathrm{OH}$ ) goes roughly as $1 / p$ for $p<1$, where $p$ is the relative accretion rate between gaseous $\mathrm{H}$ and $\mathrm{CO}$. Thus, if the gaseous $\mathrm{H}$ abundance is significantly less than that of gaseous $\mathrm{CO}$, surface $\mathrm{CO}$ will dominate over its hydrogenated forms.

Another partial comparison between our results and those of Tielens \& Whittet (1997) is afforded by calculated surface formaldehyde abundances. Tielens \& Whittet (1997) show wide variations in the formaldehyde/methanol ratio on grain surfaces, due to two factors: the parameter $p$ and an additional parameter $\phi$, which relates the efficiency of reaction between $\mathrm{H}$ and $\mathrm{CO}$ to that between $\mathrm{H}$ and formaldehyde $\left(\mathrm{H}_{2} \mathrm{CO}\right)$. In our system, the abundance of surface formaldehyde is rather high because of both the high surface abundance of $\mathrm{H}$ and the high activation energy we choose for the $\mathrm{H}+\mathrm{H}_{2} \mathrm{CO}$ reaction. A reduction in the parameter $p$ (leading to less $\mathrm{H}$ ) coupled with a reduction in the activation energy lowers the relative abundance of $\mathrm{H}_{2} \mathrm{CO}$, in qualitative agreement with the results of Tielens \& Whittet (1997).

The high solid $\mathrm{CO}_{2} / \mathrm{H}_{2} \mathrm{O}$ abundance ratio $(\approx 0.15)$ observed by ISO toward massive star-forming regions (de Graauw et al. 1996; Whittet et al. 1996) cannot be reproduced by our models at any time (see Table 2). However, we point out that ISO observations refer to regions where gas densities and temperatures are higher than the ones considered by us. In dark and quiescent clouds there is indirect observational evidence that $\mathrm{CO}_{2}$ is not one of the main grain-mantle components. In fact, along the line of sight of background stars in Taurus, observed solid $\mathrm{CO}$ features are best fitted with laboratory mixtures lacking $\mathrm{CO}_{2}$ (Chiar et al. 1995). This suggests that $\mathrm{CO}_{2}$ is preferentially formed in the proximity of embedded young stellar objects, where energetic processing of dust grains is present. A major reaction leading to surface $\mathrm{CO}_{2}$ in such regions, which possesses some activation energy $(1000 \mathrm{~K})$ and is therefore less important than the reaction in equation (10) on $10 \mathrm{~K}$ grains, is

$$
\mathrm{CO}+\mathrm{O} \rightarrow \mathrm{CO}_{2} \text {. }
$$

Finally, our modified gas-grain model is still far from complete. Our gas-phase chemistry, based on the "new standard model" (Bettens et al. 1995), does not include a representative sample of rapid neutral-neutral reactions. Our grain surface chemistry does not contain very effective desorption mechanisms and photochemical processes, which may be crucial for molecular synthesis under certain conditions. These and other improvements will be 
addressed in future work. In the more immediate future, we plan to use our modified rate approach to study the role of deuterium on grain surfaces. We are particularly interested in comparison with the simplified Monte Carlo approach of Charnley et al. (1997).

E. H. acknowledges the support of the National Science Foundation for his research program in astrochemistry.
Funds from this source of support have been used to pay for the visit of O. M. S. to Ohio State University. E. H. also wishes to acknowledge the Ohio Supercomputer Center for computer time on their Cray Y-MP8 and the GNA for their support of his delightful stay at the Osservatorio di Arcetri. P. C. acknowledges partial support from the ASI, through grant ARS-96-66, and from the CNR, through grants 96/ 00317 and 97.00018.CT02.
Allen, M., \& Robinson, G. W. 1977, ApJ, 212, 396

Bettens, R. P. A., Lee, H.-H., \& Herbst, E. 1995, ApJ, 443, 664

Brown, P. D. 1990, MNRAS, 243, 65

Brown, P. D., \& Charnley, S. B. 1990, MNRAS, 244, 432

Caselli, P., Hasegawa, T. I., \& Herbst, E. 1993, ApJ, 408, 548 .1994, ApJ, 421, 206 1998, ApJ, 495, 309

Charnley, S. B., Tielens, A. G. G. M., \& Rodgers, S. D. 1997, ApJ, 482, L203

Chiar, J. E., Adamson, A. J., Kerr, T. H., \& Whittet, D. C. B. 1995, ApJ, 455,234

de Graauw, Th., et al. 1996, A\&A, 315, L345

d'Hendecourt, L. B., Allamandola, L. J., \& Greenberg, J. M. 1985, A\&A, 152,130

Hasegawa, T. I., \& Herbst, E. 1993a, MNRAS, 261, 83

. 1993b, MNRAS, 263, 589

Hasegawa, T. I., Herbst, E., \& Leung, C. M. 1992, ApJS, 82, 167

Hollenbach, D. J., \& Salpeter, E. E. 1971, J. Chem. Phys., 53, 79

\section{REFERENCES}

Lee, H.-H., Bettens, R. P. A., \& Herbst, E. 1996, A\&AS, 119, 111

Pickles, J. B., \& Williams, D. A. 1977, Ap\&SS, 52, 443

Shalabiea, O. M., \& Greenberg, J. M. 1994, A\&A, 290, 266

Shalabiea, O. M., Herbst, E., \& Caselli, P. 1997, in Formation and Evolution of Solids in Space, ed. J. M. Greenberg (Dordrecht: Kluwer), in press

Tielens, A. G. G. M., \& Allamandola, L. J. 1987, in Interstellar Processes, ed. D. J. Hollenbach \& H. A. Thronson (Dordrecht: Reidel), 397

Tielens, A. G. G. M., \& Charnley, S. B. 1997, Origins of Life and Evolution of the Biosphere, 27, 34

Tielens, A. G. G. M., \& Hagen, W. 1982, A\&A, 114, 245

Tielens, A. G. G. M., \& Whittet, D. C. B. 1997, in Molecules in Astrophysics: Probes and Processes, ed. E. F. van Dishoeck (Dordrecht: Kluwer), 45

Whittet, D. C. B., et al. 1996, A\&A, 315, L357

Willacy, K., \& Williams, D. A. 1993, MNRAS, 260, 635

Note added in proof.-Solid $\mathrm{CO}_{2}$ has now been detected in a quiescent cloud toward Elias 16 (D. C. B. Whittet, et al., ApJ, 498 , L159 [1998]). The column density is equivalent to $\approx 18 \%$ of the column density of water ice and cannot be accounted for by our model results, which are approximately 2 orders of magnitude too low. It should be noted, however, that Elias 16 is a field star, and the line of sight toward it may not intercept a dense cloud core. It is possible that photo chemistry may be playing an appreciable role. 